\title{
DISASTERS RELATED TO COLD CLIMATE
}

\section{5}

\section{Disasters Related to Cold Climate}

\section{Renstrom $B$}

Ostersund

Froson, Sweden

In December $1718,3,000$ of the Armfelt's Caroliners (soldiers of Charles XII) died in the high mountains when returning from an expedition to Norway. The other 2,000 contracted all sorts of cold injuries.

During the winter of 1812, Emperor Napoleon lost thousands of soldiers on an expedition to Moscow. The therapy was snow rubbing followed by amputations.

In 1912, the Titanic struck an iceberg and sank. All of the 1,489 people in the water were dead in their lifebelts.

On 8 February 1978, a group of nine young people died during a storm in a snow cave in the high mountains of (my home country) Jamtland. The only survivor eventually lost his hands and feet.

On 12 May 1986, nine of 13 climbers died in a snow cave during a blizzard on the summit of Mt. Hood in Oregon, in the western United States. All nine victims were treated using cardiac bypass machines.

\section{6}

\section{The Avalanche in Vassdalen, Norway}

Rostrup $M,{ }^{*}$ Gilbert $M$, ${ }^{* *}$ Stalsberg $H^{* * *}$

* Medical Department, Ulleval Hospital

University of Oslo, Oslo, Norway

** Department of Anesthesiology, Ulleval Hospital

University of Oslo, Oslo, Norway

*** Department of Pathology, Tromso Regional Hospital University of Tromso

Oslo, Norway

In northern Norway, 31 soldiers were caught in a snow avalanche. One was not buried, 13 were partly buried, and 17 were completely buried by the snow masses. Only one of theburied completely soldiers survived. He had moderate hypothermia on admission to the hospital after having been buried in snow for three hours. Five of the 13 partly buried had physical traumas. None of the nine attempts to resuscitate succeeded. Self-rescue and rescue by friends were most important to the soldiers who survived.

Consistent autopsy findings were prominent lung edema, moderate cerebral edema, extreme contraction of the left ventricle, petechiae in the superior vena cava drainage area, and acute congestion in the lungs and kidneys. The immediate cause of death in most cases was general body compression with acute respiratory and circulatory failure, not hypothermia.

\section{7}

\section{Hypothermia in the Sea}

Jungnelius $B$

Anaesthetic Department, The Central Hospital

Visby, Sweden

Disasters at sea often force crew and passengers to abandon ship and enter liferafts or lifeboats. When doing so, they expose themselves to cold water and winds. During the colder seasons this, in combination with rough weather conditions, has taken many lives in the Baltic Sea in recent years.

This presentation takes a look at individual risk parameters and problems related to rescue work with helicopter or ship, and presents experiences from such work in recent disasters.

\section{8}

\section{Whole Body Cooling of Accident Patients During Terrain Transportation in Cold}

Anttomen H, Hiltunen E, Hassi J, Pihlajaniemi $R^{*}$

Regional Institute of Occupational Health

Northern Command Headquarters

Oulu, Finland

Objectives: The evaluation of cooling in accident patients during terrain transportation was made to predict the need for insulation and safe exposure time.

Methods: By material measurements with sweating cylinders and hot plates in different thermal conditions, nine different protective covering systems were measured. Four systems were selected for test subject measurements in a climatic chamber ( 5 hours $[\mathrm{h}],-20^{\circ} \mathrm{C}, 1 \mathrm{~m} / \mathrm{s}$ and $5 \mathrm{~m} / \mathrm{s}$ ) using the temperature (11) and heat flux (8) sensors. A physical model predicting the amount of cooling also was tested. The comparison between the traditional three-blanket system, the blanket system with wind covering, and the modern covering system was made by using the cylinder method.

Results: The change in insulation $\left(0.80-1.04 \mathrm{~m}^{2} \mathrm{~K} / \mathrm{W}\right)$ in the wind condition were $53 \%, 4 \%$, and $20 \%$ respectively. In test subject measurements, in comparison to the traditional stretcher with three blankets with and without wind covering and the modern pulkha with and without air space under the wind covering, the wind changed the insulation $(0.48-0.81$ $\mathrm{m}^{2} \mathrm{~K} / \mathrm{W}$ ) of the systems by $5 \%$ to $25 \%$. The local skin temperatures varied much when using different systems, e.g., the temperatures of toes ranged from $11^{\circ} \mathrm{C}$ to $26^{\circ} \mathrm{C}$. According to the recommendations of critical cooling $(20 \mathrm{~J} / \mathrm{g})$, maximum exposure times were predicted to be from $1.8 \mathrm{~h}$ to $23 \mathrm{~h}$ with the different covering systems. 